\title{
IMPLEMENTASI LOGIKA FUZZY DALAM MENENTUKAN JURUSAN BAGI SISWA BARU SEKOLAH MENENGAH KEJURUAN (SMK) NEGERI 1 AIR PUTIH
}

\author{
Muhammad Dedi $\operatorname{Irawan}^{1}$, Herviana $^{2}$ \\ 1,2, Fakultas Teknik Jurusan Teknik Informatika Universitas Asahan \\ J1. Jend Ahmad Yani Kisaran Sumatera Utara \\ ${ }^{1}$ temansejati.dediegmail.com, ${ }^{2}$ herviana.st90@gmail.com
}

\begin{abstract}
Abstrak - Proses pemilihan jurusan oleh calon siswa oleh SMK Negeri 1 Air Putih dilakukan dengan cara masih manual. Siswa ada yang merasa tidak cocok dengan minatnya ketika memperoleh pelajaran di sekolahnya, hal ini mengakibatkan siswa pindah sekolah dan ada juga yang putus sekolah. Hal lain yang juga dapat berakibat seperti siswa yang pindah dan putus sekolah. Didalam penelitian ini dibangun Sistem implementasi logika fuzzy dengan menggunakan metode Tsukamoto. Dari hasil penelitian di dapatkan hasil bahwa metode Tsukamoto mampu memberikan rekomendasi jurusan yang sesuai matapelajaran yang memiliki nilai yang tinggi.
\end{abstract}

Kata kunci - Fuzzy Tsukamoto, Logika Fuzzy, Calon Siswa Baru.

\section{PENDAHULUAN}

Komputer dianggap dapat memberikan solusi kepada manusia dalam pengerjaan suatu masalah. Berkembangnya suatu teknologi di sekitar kita dapat dijadikan tolak ukur terhadap kemajuan suatu bangsa. Di Indonesia perkembangan teknologi dikategorikan tidak terlalu cepat dan efisien.

Sama halnya dengan lembaga pendidikan seperti pendidikan di SMK Negeri 1 Air Putih kerap kali membutuhkan suatu bentuk keputusan dalam menentukan jurusan yang sesuai untuk siswa/siswi di SMK tersebut. Keputusan yang diambil dalam memilih jurusan mungkin hampir benar sesuai dengan kemampuan bakat dan minat siswa atau mungkin juga salah. Penerapan yang dibuat harus benar-benar dipertimbangkan dengan pilihan yang sesuai untuk pengambil jurusan tersebut.

Terkadang teknologi pendaftaran khususnya dalam memilah data murid memerlukan adanya sebuah sistem yang mendukung dan bisa memilih data yang sesuai ketika ada data yang ingin di masukkan. Sistem ini selalu membutuhkan metode yang tepat. Fuzzy banyak digunakan dalam pendukung pengambilan keputusan seperti pada beberapa penelitian yang telah dilakukan yang diantaranya Muntaha, M. S. (2010).

Dalam kenyataannya masih banyak siswa baru SMK yang kebingungan dalam memilih jurusan. Fenomena ini sering terjadi pada siswa baru yang dimana terkadang salah dalam memilih jurusan, terkadang siswa baru memilih jurusan tersebut bukan berdasarkan keinginannya ataupun kemampuannya akan tetapi hanya terikut kepada temannya. Belum lagi bila terdapat kesalahan data dan siswa meminta untuk berganti jurusan karena hasil yang didapat tidak sesuai dengan yang mereka inginkan,

Dari penelitian ini, diharapkan dapat menentukan kemampuan yang tepat untuk mendukung dalam proses pemilihan jurusan dan pemberian rekomendasi pemilihan jurusan sesuai minat dan kemampuan dengan mengunakan metode logika fuzzy tsukamoto untuk menentukan hubungan antara bakat dan akademik.

Maka dari itu penulis menggunakan metode fuzzy tsukamoto untuk menentukan jurusan bagi siswa baru Sekolah Menengah Kejuruan (SMK) N 1 Air Putih, Dimana metode fuzzy tsukamoto ini mampu mengelompokkan data berdasarkan input yang telah dipilih dan menerapkan aturan yang telah ditetapkan sehingga bisa menghasilkan output pengelompokan data seperti yang diharapkan.

Dengan melihat kekurangan tersebut, penulis memiliki gagasan yang akan membantu siswa baru dalam menentukan jurusan yang sesuai dengan minat dan kemampuannya. Dalam penerapannya ke depan diharapkan masalah dalam menentukan jurusan dapat diatasi. Oleh karena itu, penulis mengangkat judul "IMPLEMENTASI LOGIKA FUZZY DALAM MENENTUKAN JURUSAN BAGI SISWA BARU SEKOLAH MENENGAH KEJURUAN (SMK) NEGERI 1 AIR PUTIH”.

\section{LANDASAN TEORI}

A. Implementasi

Implementasi adalah suatu tindakan atau pelaksanaan dari sebuah rencana yang sudah disusun secara matang dan terperinci. Implementasi biasanya dila-kukan setelah perencanaan sudah diang-gap fix. Secara sederhana, implementasi bisa diartikan pelaksanaan atau penerapan dan implementasi adalah perluasan aktivitas yang saling menyesuaikan antara sistem yang asli dengan sistem yang rekayasa (Rahma Farah Ningrum, 2014).

Setelah sistem dianalisa dan dirancang, kemudian sistem siap diterapkan atau diimplementasikan. Implementasi merupakan tahap di mana sistem informasi sudah digunakan oleh 
pengguna (sebelum benar-benar bisa digunakan dengan baik oleh pengguna).

Sistem wajib melewati tahap pengujian dengan tujuan agar sistem terjamin tanpa kendala fatal yang timbul ketika pengguna memakai sistem tersebut. Adapun tujuan diadakannya implementasi sistem adalah :

1. Membuat desain sistem selama melakukan penelitian analisa.

2. Menguji serta mendokumentasi prosedur dan program yang dibutuhkan.

3. Menyelesaikan desain sistem yang sudah disetujui.

4. Memperhitungkan sistem yang sudah dibuat sesuai kebutuhan pengguna.

\section{B. Logika Fuzzy}

Menurut Muhammad Dedi Irawan (2017), Teori tentang fuzzy set atau himpunan samar pertama kali dikemukakan oleh Lotfi Zadeh sekitar tahun 1965 pada sebuah makalah yang berjudul 'Fuzzy Set'. Setelah itu, sejak pertengahan 1970-an, para peneliti Jepang berhasil mengaplikasikan teori ini kedalam permasalahan teknis. Logika fuzzy adalah peningkatan dari logika boolean yang berhadapan dengan konsep kebenaran sebagian. Saat logika klasik menyatakan segala hal dapat didefinisikan dalam istilah biner

Menurut Akbar Ariya Caraka, dkk (2015), logika fuzzy adalah metodologi sistem kontrol pemecahan masalah yang cocok diterapkan pada sistem, mulai dari sistem yang sederhana sampai sistem yang rumit atau kompleks. Metodologi ini dapat diterapkan pada perangkat keras, perangkat lunak, atau kombinasi keduanya. Dalam Logika Klasik dinyatakan bahwa segala sesuatu bersifat biner, yang artinya adalah hanya dua kemungkinan yaitu "ya atau tidak", "benar atau salah", "baik atau buruk" dan lain-lain. Oleh karena itu, semua ini dapat mempunyai nilai keanggotaan 0 atau 1. Akan tetapi, dalam logika fuzzy memungkinkan nilai keanggotaan berada di antara 0 atau 1 , artinya bisa saja suatu keadaan mempunyai dua nilai "ya dan tidak", "benar dan salah", "baik dan buruk" secara bersamaan, namun besar nilainya tergantung pada bobot keanggotaan yang dimilikinya.

Dalam logika fuzzy terdapat beberapa metode yang bisa digunakan untuk memprediksi perilaku konsumen. Salah satu metode yang dapat digunakan untuk memprediksi perilaku konsumen adalah metode Tsukamoto. Metode ini dipilih karena sifatnya yang fleksibel, dan memiliki toleransi pada data yang ada. Kelebihan dari metode ini yaitu lebih cepat dalam melakukan komputasi, lebih intuitif, diterima oleh banyak pihak, lebih cocok untuk masukan yang diterima dari manusia bukan oleh mesin. Setiap aturan yang berbentuk IF-THEN direpresentasikan dengan himpunan fuzzy dengan fungsi keanggotaan yang monoton. Sebagai hasilnya, output dari setiap aturan diberikan secara tegas berdasarkan alpha predikat $(\alpha)$, kemudian diperoleh hasil akhir dengan menggunakan rata-rata terpusat.
Logika fuzzy adalah metodologi sistem kontrol pemecahan masalah yang cocok diterapkan pada sistem, mulai dari sistem yang sederhana sampai sistem yang rumit atau kompleks. Logika fuzzy dapat diterapkan dalam berbagai bidang, diantaranya yaitu pada sistem diagnosis penyakit (dalam bidang kedokteran), pemodelan sistem pemasaran, riset operasi (dalam bidang ekonomi), kendali kualitas air, prediksi adanya gempa bumi dan lain-lain. Logika fuzzy adalah suatu cara yang tepat untuk memetakan suatu ruang input ke dalam suatu ruang output. Selain itu logika fuzzy juga dapat diartikan suatu cara yang tepat untuk memetakan suatu ruang input kedalam suatu ruang output.

\section{Fuzzy Tsukamoto}

Menurut Chabibi Aulia Rahman Al Hasmy ( dalam Muhammad Dedi Irawan, 2017), Pada metode Tsukamoto, setiap konsekuen pada aturan yang berbentuk IF-THEN harus direpresentasikan dengan suatu himpunan fuzzy dengan fungsi keanggotaan yang monoton. Sebagai hasilnya, output hasil inferensi dari tiap-tiap aturan diberikan secara tegas (crisp) berdasarkan $\alpha$-predikat (fire strength). Hasil akhirnya diperoleh dengan menggunakan rata-rata terbobot.

Menurut Kusumadewi (dalam Hanis Setiawati Permatasari1, Awang Harsa Kridalaksana, dan Addy Suyatno, 2015, dalam membangun sebuah sistem fuzzy dikenal beberapa metode penalaran, antara lain adalah metode Tsukamoto, metode Mamdani dan metode Sugeno. Pada metode Tsukamoto, setiap konsekuen pada aturan berbentuk IF-THEN harus direpresentasikan dengan suatu himpunan fuzzy dengan fungsi keanggotaan monoton. Sebagai hasilnya, output hasil inferensi dari tiap-tiap aturan diberikan dengan tegas (crisp) berdasarkan $\alpha$-predikat (fire strength). Hasil akhirnya diperoleh dengan menggunakan rata-rata terbobot.

\section{Database}

Menurut Ari Maizary (dalam Angga Suryanto, 2012), database adalah ukuran informasi yang tersimpan secara elektronis yang disimpan disuatu file-file yang mempunyai kaitan antara satu file dengan file lainnya sehingga membentuk satu hubungan data untuk menginformasikan satu perusahaan, instansi dalam batasan tertentu. Bila terdapat file yang tidak dapat dipadukan atau dihubungkan dengan file lainya berarti file tersebut bukanlah kelompok dari database, maka file tersebut membentuk satu database tersendiri.

Menurut Abdul Kadir (dalam Dina Khusnia, Berliana Kusuma Riasti, 2014), database menyatakan merupakan suatu bentuk pengelolaan data yang ditujukan agar pengaksesan terhadap data dapat dilakukan dengan mudah.

Database yaitu kumpulan file-file yang berhubungan satu dengan yang lainnya, diatur sedemikian rupa sehingga dapat digunakan oleh beberapa program aplikasi database. Database merupakan salah satu komponen yang penting dalam 
sistem informasi karena merupakan basis dalam menyediakan informasi bagi para pemakai. Penerapan basis data dalam sistem informasi disebut dengan database sistem.

Menurut penulis sistem basis data (System Database) adalah suatu sistem informasi yang mengintergrasikan kumpulan dari data yang saling berhubungan satu dengan yang lainnya dan membantunya tersedia bagi para aplikasi yang bermacam-macam di dalam organisasi.

\section{E. XАMPP}

Menurut Alan Nur Aditya (dalam Dwi Priyanti dan Siska Iriani, 2013), XAMPP adalah merupakan bagian dari beberapa program yang dikompilasi dan banyak mendukung beberapa sistem operasi. Berfungsi sebagai server yang dapat berdiri sendiri (localhost), dan terdiri atas program Apache HTTP Server, MySQL database. Nama XAMP merupakan singkatan dari $\mathrm{X}$ (empat system operasi apapun), Apache, MySQL, PHP dan Perl. Program ini dapat melayani tampilan halaman web dinamis dan tersedia dalam GNU General Public License dan bebas, merupakan web server yang mudah digunakan.

\section{F. Java Netbeans IDE}

Menurut Bay Haqi dan Jonser Sinaga, (2018), NetBeans adalah Integrated Development Environment (IDE) berbasiskan Java dari Sun Microsystems yang berjalan di atas Swing. Swing sebuah teknologi Java untuk pengembangan aplikasi Desktop yang dapat bejalan di berbagai macam platforms seperti Windows, Linux, Mac OS X and Solaris. Suatu IDE adalah lingkup pemrograman yang diintegrasikan kedalam suatu aplikasi perangkat lunak yang menyediakan pembangun Graphic User Interface (GUI), suatu text atau kode editor, suatu compiler atau interpreter dan suatu debugger. Netbeans merupakan software development yang Open Source, dengan kata lain software ini di bawah pengembangan bersama, bebas biaya NetBeans salah satu aplikasi Open Source yang sukses dengan pengguna yang sangat luas, komunitas yang terus tumbuh karena kode yang terbuka tersebut, dan memiliki hampir 100 mitra. Sun Microsystems mendirikan proyek kode terbuka NetBeans pada bulan Juni 2000 dan terus menjadi sponsor utama. Saat ini terdapat dua produk : NetBeans IDE dan NetBeans Platform.

The NetBeans IDE adalah sebuah apalikasi untuk mengkoding, mengompilasi, mencari kesalahan dan mengembangkan program. Netbeans IDE ditulis dalam bahasa Java, namun dapat mendukung bahasa pemrograman lain. Terdapat banyak modul untuk memperluas Netbeans IDE. Untuk membuat aplikasi berbasis desktop tersedia juga NetBeans Platform merupakan fondasi yang modular dan dapat diperluas yang dapat digunakan sebagai perangkat lunak dasar. NetBeans memiliki GUI Builder yang sangat kompetebel dengan Swing karena memang langsung dikembangkan oleh Sun yang notabenenya sebagai pengembang Swing. Kekurangan dalam aplikasi NetBeans GUI Builder hanya mensupport satu pengembangan Java GUI, yaitu Swing, yang padahal ada Java GUI yang dikembangkan oleh eclipse yang bernama SWT dan JFace yang sudah cukup populer. NetBeans mempatenkan source untuk Java GUI yang sedang dikerjakan dalam sebuah Generated Code, sehingga programmer tak dapat mengeditnya secara manual.

Menurut (Heiko Bock, 2009) NetBeans IDE adalah aplikasi bebas tanpa ada batasan bagaimana menggunakannya. Mitra ISV dapat juga digunakan untuk membuat tools dan solusi sendiri sesulai plug-in. Kode sumber tersedia dengan lisensi Common Development and Distribution License (CDDL).

\section{G. $\quad$ UML (Unified Modeling Language)}

Menurut Windu Gata dan Grace (dalam Ade Hendini, 2016), Unified Modeling Language (UML) adalah bahasa spesifikasi standar yang dipergunakan untuk mendokumentasikan, menspesifikasikan dan membanngun perangkat lunak. UML merupakan metodologi dalam mengembangkan sistem berorientasi objek dan juga merupakan alat untuk mendukung pengembangan sistem.

Menurut Fowler (2005:1), Unified Modeling Language (UML) adalah keluarga notasi grafis yang didukung oleh meta-model tunggal, yang membantu pendepenelitianan dan desain sistem perangkat lunak, khususnya sistem yang dibangun menggunakan Pemrograman Berorientasi Objek (PBO). Definisi ini merupakan definisi yang sederhana. Pada kenyataannya, pendapat orang-orang tentang UML berbeda satu sama lain. Hal ini dikarenakan oleh sejarahnya sendiri dan oleh perbedaan persepsi tentang apa yang membuat sebuah proses rancang-bangun perangkat lunak efektif.

Abstraksi konsep dasar UML terdiri dari structural classification, dynamic behavior, dan model management. UML mendefinisikan diagram-diagram sebagai berikut :
1. Use Case Diagram
2. Class Diagram
3. Statechart Diagram
4. Activity Diagram
5. Sequence Diagram
6. Collaboration Diagram
7. Component Diagram
8. Deployment Diagram
9. Package Diagram

Unified Modeling Language (UML) merupakan strandar yang relatif terbuka yang dikontrol oleh Object Management Group (OMG), sebuah konsorsium terbuka yang terdiri dari banyak perusahaan. OMG dibentuk untuk membuat standarstandar yang mendukung interoperabilitas, khusunya interoperabilitas sistem berorientasi objek. OMG mungkin lebih dikenal dengan standar-standar 
COBRA atau Common Object Request Broker Architecture (Diah Puspitasari, 2015).

\section{METODE PENELITIAN}

\section{A. Rancangan Penelitian}

Dalam melakukan suatu penelitian sangat perlu dilakukan perencanaan dan pelaksanaan penelitian, agar penelitian yang dilakukan dapat berjalan dengan baik dan sistematis.

Rancangan penelitian adalah suatu kesatuan, rencana terinci dan spesifik mengenai cara memperoleh, mengalisis dan menginterprestasi. Rancangan penelitian memberikan gambaran tentang apa yang harus dilakukan dan kesulitan- kesulitan yang dihadapi saat penelitian. Dengan rancangan penelitian, seseorang peneliti mampu mengambil sikap dan keputusan yang tepat dalam mengatasi masalah penelitian.

Pada penelitian ini penulis menjelaskan perancangan dan implementasi dalam pembuatan aplikasi menentukan jurusan bagi siswa baru Sekolah Menengah Kejuruan (SMK) Negeri 1 Air Putih dengan logika fuzzy berbasis NetBeans ini adalah sebagai berikut :

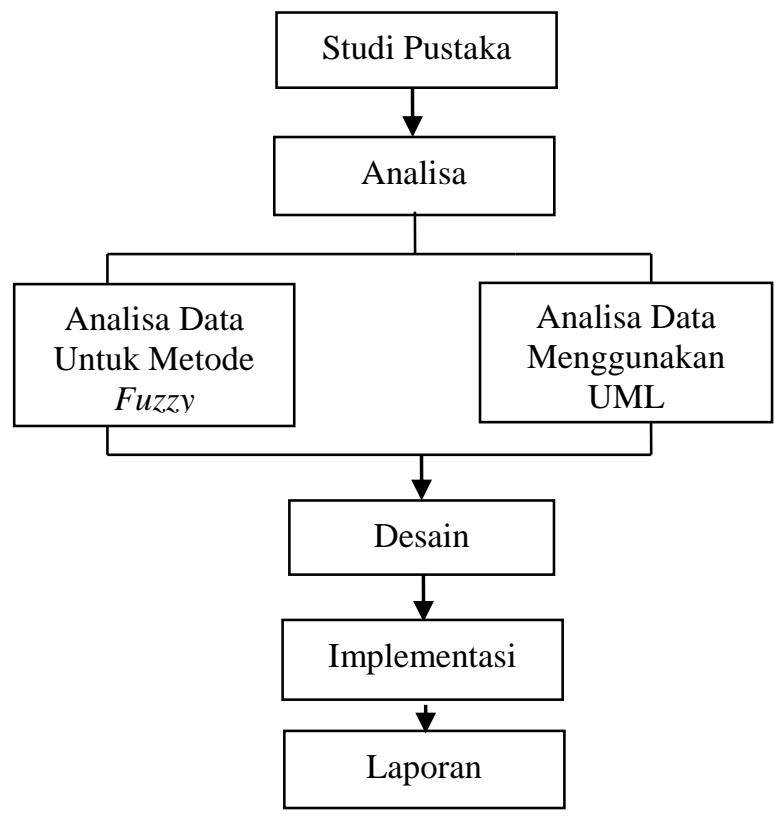

Gambar 1 Kerangka Kerja

\section{B. Studi Pustaka}

Studi pustaka terdiri dari hasil nilai dari calon siswa-siswi baru yang akan memasuki Sekolah Menengah Kejuruan (SMK) N 1 Air Putih yang didapat dari sekolah sebelum nya dan juga bahan dapat di kutip dari penelitian, internet dan jurnal yang akan diimplementasikan kedalam penelitian pada setiap bab yang akan dirancang oleh penulis.

\section{Analisa}

Analisa dalam hal ini adalah fase pengembangan sistem yang menentukan sistem informasi yang harus dilakukan untuk memecahkan masalah yang sudah ada dengen mempelajari sistem dan proses kerjanya untuk mengidentifikasi kekuatan, kelemahan, dan peluang untuk perbaikan serta mengidentifikasikan penyebabnya, menentukan solusi, dan mengidentifikasikan kebutuhan informasi yang diperlukan sistem. Adapun beberapa analisa yang akan dibuat antara lain adalah :

a. Analisa data untuk metode fuzzy

Penulis akan menganalisa data yang telah ada dan menyelesaikan dengan metode fuzzy, yang di mana setiap siswa harus memiliki kreteria yaitu, nilai rata-rata UN, nilai rata-rata UAS dan nilai rata-rata Testing.

b. Analisa data menggunakan UML (Unified Moddelling Language)

Penulis mennganalisa data menggunakan Use Case Diagram, Class Diagram, Activity Diagram, Sequence Diagram.

\section{Desain}

Desain adalah sikap atau perhatian terhadap suatu bentuk sehingga mampu menguraikan menjadi berbagai bentuk bagian, serta mengenal kaitan antar bagian tersebut dalam keseluruhannya. Analisa desain juga dapat di uraikan sebagai kamampuan memecahkan atau menguraikan suatu materinatau informasi menjadi komponen-komponen yang lebih kecil sehingga lebih mudah dipahami.

\section{E. Implementasi}

Implementasi adalah tahapan yang dilaksanakan dalam meletakkan sistem supaya siap dioperasikan. Adapun komponen dibutuhkan dalam implementasi sistem yaitu perengkat keras (Hardware), perangkat lunak (Software). Adapun hardware dan software yang dibutuhkan adalah sebagai berikut :

a. Perangkat Keras (Hardware)

1) Laptop Acer Aspire 4734

2) Memori 2 GB DDR3 Memory.

3) $500 \mathrm{~GB}$ HDD.

4) Processor Intel® Core $^{\mathrm{TM}}$ i3-380M

5) $R A M 2048 \mathrm{MB}$

b. Perangkat Lunak (Software)

1) Sistem Operasi Windows 7.

2) Microsoft Word 2007.

3) NetBeans IDE 8.2.

4) XAMPP 2.5.8 sebagai Database Management System (DBMS).

5) MySQL.

\section{F. Obyek Penelitian}

Dalam membuat laporan penelitian ini penulis melakukan penelitian di Sekolah Menegah Kejuruan (SMK) Negeri 1 Air Putih yang terletak di Kabupaten BatuBara. 


\begin{tabular}{|c|c|c|}
\hline Variabel & Semesta Pembicaraan & Keterangan \\
\hline Nilai Siswa & {$[0-100]$} & Nilai Rata-Rata \\
\hline
\end{tabular}

G. Defenisi Operasional Variabel

Definisi variabel adalah penentuan variabel yang menyebabkan atau memengaruhi, yaitu faktorfaktor sehingga menjadi variabel yang dapat diukur, dimanipulasi atau dipilih oleh penulis sehingga dapat menentukan hubungan antara fenomena yang diobservasi dan diamati dalam melakukan penelitian.

Operasional variabel berisikan indikatorindikator dari suatu variabel yang memungkinkan penulis mengumpulkan data yang relevan untuk variabel tersebut. Variabel penelitian merupakan objek penelitian atau apa yang menjadi titik perhatian suatu penelitian. Variabel penelitiannya adalah menggunakan variabel fuzzy Tsukamoto.

\section{H. Teknik Pengumpulan Data}

Untuk mengumpulkan data mengenai objek penelitian digunakan metode pengumpulan data yaitu diperoleh secara langsung dari sumber penelitian yaitu calon siswa-siswi baru yang akan memasuki Sekolah Menengah Kejuruan (SMK) N 1 Air Putih dan juga data yang diperoleh dengan mengumpulkan terlebih dahulu teori yang ada kaitannya dengan masalah yang diteliti dan data tersebut didapatkan dengan cara mencari browsing internet, dan pembandingan masalah yang penulis bahas, juga sebagai pendukung data primer dan skunder..

\section{I. $\quad$ Metode Analisis Data}

Sistem yang akan dibangun adalah sistem yang diimplementasikan dengan menggunakan metode fuzzy Tsukamoto yang dimana observasi dilakukan di SMK Negeri 1 Air Putih. Rancangan ini telah terformat sebelum kegiatan pengumpulan data dan pada saat merumuskan masalah yang telah dibuat. Yang dimana rancangan analisis data hasil penelitian telah dipersiapkan mulai dari penentuan jenis data yang akan didapat dan dikumpulkan dari sumber-sumber yang telah ditemui, dan rumusan masalah yang akan diuji telah dibuat.

\section{J. Metode Analisa Sistem}

Metode analisa sistem yang digunakan oleh penulis dalam memecahkan masalah dalam menentukan jurusan bagi siswa baru SMK Negeri 1 Air Putih adalah UML, anatar lain Use Case Diagram, Class Diagram, Activity Diagram, Sequence Diagram.

\section{ANALISA DAN PEMBAHASAN}

\section{A. Penentuan Input dan Output}

Untuk menentukan input dan output dapat diperoleh dari semesta pembicaraan.

\section{Menentukan Semesta Pembicaraan}

Pada objek yang diteliti diperoleh dari nilainilai siswa yang diperoleh pada pengumpulan data
Table 1 Semesta pembicaraan

\section{Menentukan Input}

Input yang diperoleh terlihat pada tabel 2 berikut. Yang dimana nilai yang akan dimasukan antara lain :

Tabel 2 Penentuan Input

\begin{tabular}{|c|c|c|c|}
\hline Fungsi & Variabel & $\begin{array}{c}\text { Semesta } \\
\text { Pembicaraan }\end{array}$ & Keterangan \\
\hline \multirow{4}{*}{ Input } & Nilai IPA & {$[0-100]$} & Jumlah Nilai \\
\cline { 2 - 4 } & Nilai M.M & {$[0-100]$} & Jumlah Nilai \\
\cline { 2 - 4 } & Nilai B.Ing & {$[0-100]$} & Jumlah Nilai \\
\cline { 2 - 4 } & $\begin{array}{c}\text { Nilai } \\
\text { B.Indo }\end{array}$ & {$[0-100]$} & Jumlah Nilai \\
\hline
\end{tabular}

3. Menentukan Output

Untuk menentukan output diperoleh dari masing-masing input. Output yang diperoleh terlihat pada tabel 3 berikut.

Tabel 3 Penentuan Output

\begin{tabular}{|c|c|c|c|}
\hline Fungsi & Variabel & $\begin{array}{c}\text { Semesta } \\
\text { Pembicaraan }\end{array}$ & Keterangan \\
\hline \multirow{4}{*}{ Output } & TKJ & {$[0-100]$} & Jumlah Nilai \\
\cline { 2 - 4 } & RPL & {$[0-100]$} & Jumlah Nilai \\
\cline { 2 - 4 } & TSM & {$[0-100]$} & Jumlah Nilai \\
\cline { 2 - 4 } & TBO & {$[0-100]$} & Jumlah Nilai \\
\cline { 2 - 4 } & TKR & {$[0-100]$} & Jumlah Nilai \\
\cline { 2 - 4 } & KI & {$[0-100]$} & Jumlah Nilai \\
\hline
\end{tabular}

B. Pembentukan Logika Fuzzy Tsukamoto

Setelah ditentukan semesta pembicaraan, maka langkah selanjutnya menentukan aturan fuzzy dengan metode Tsukamoto. Untuk mendapatkan nilai output dari pendapatan akhir dengan aturan fuzzy Tsukamoto dilakukan dengan pembentukan himpunan fuzzy dan derajat keanggotaannya (fuzzifikasi), penentuan rules, penalaran (inferensi) dan defuzzifikasi (defuzzification).

\section{Fuzzyfikasi}

Fuzzifikasi (fuzzification) merupakan proses memetakan nilai ke dalam himpunan fuzzy dan menentukan derajat keanggotaannya di dalam himpunan fuzzy. Himpunan fuzzy dan derajat keanggotaan (member function) yang digunakan pada tiap variabel fuzzy ditentukan berdasarkan data. 
Tabel 4 Himpunan Input Fuzzy

\begin{tabular}{|c|c|c|}
\hline Nama Variabel & Himpunan Input Fuzzy & Domain \\
\hline \multirow{4}{*}{ Nilai IPA } & Cukup & {$[40-70]$} \\
\cline { 2 - 3 } & Baik & {$[55-85]$} \\
\cline { 2 - 3 } & Sangat Baik & {$[70-100]$} \\
\hline \multirow{4}{*}{ Nilai M.M } & Cukup & {$[40-70]$} \\
\cline { 2 - 3 } & Baik & {$[55-85]$} \\
\cline { 2 - 3 } Nilai B.Indo & Sangat Baik & {$[70-100]$} \\
\cline { 2 - 3 } & Cukup & {$[40-70]$} \\
\cline { 2 - 3 } & Baik & {$[55-85]$} \\
\hline \multirow{3}{*}{ Nilai B.Ing } & Cuat Baik & {$[70-100]$} \\
\cline { 2 - 3 } & Baik & {$[40-70]$} \\
\cline { 2 - 3 } & Sangat Baik & {$[70-100]$} \\
\hline
\end{tabular}

a. Fungsi Derajat Keanggotaan $(\mu) \mathrm{V}$ ariabel Input Nilai IPA

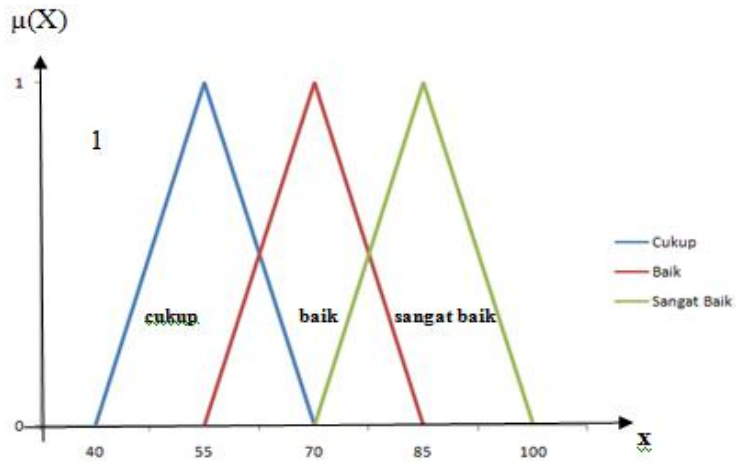

Gambar 2 Representas Fungsi Derajat Keanggotaan ( $\mu$ ) Variabel Input Nilai IPA

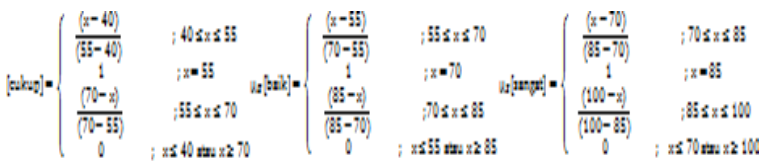

b. Fungsi Derajat Keanggotaan $(\mu) \mathrm{V}$ ariabel Input Nilai Matematika

$\mu(\mathrm{X})$

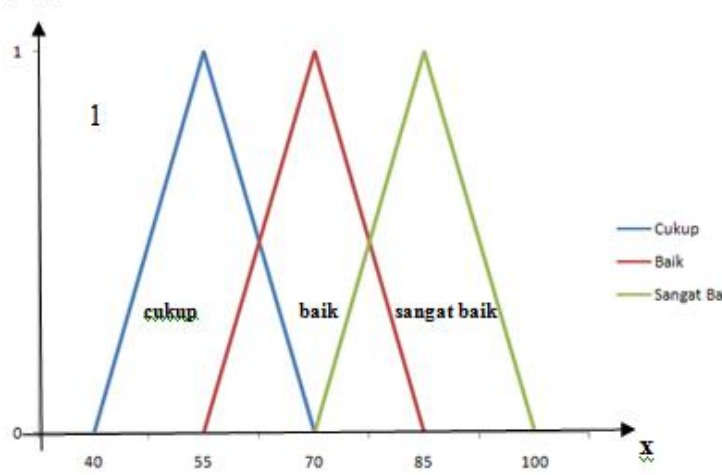

Gambar 3 Representas Fungsi Derajat Keanggotaan ( $\mu$ ) V ariabel Input Nilai Matematika.

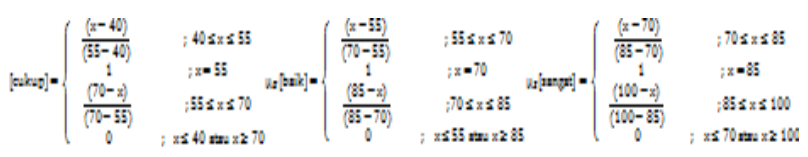

c. Fungsi Derajat Keanggotaan $(\mu) \mathrm{V}$ ariabel Input Nilai Bahasa Indonesia

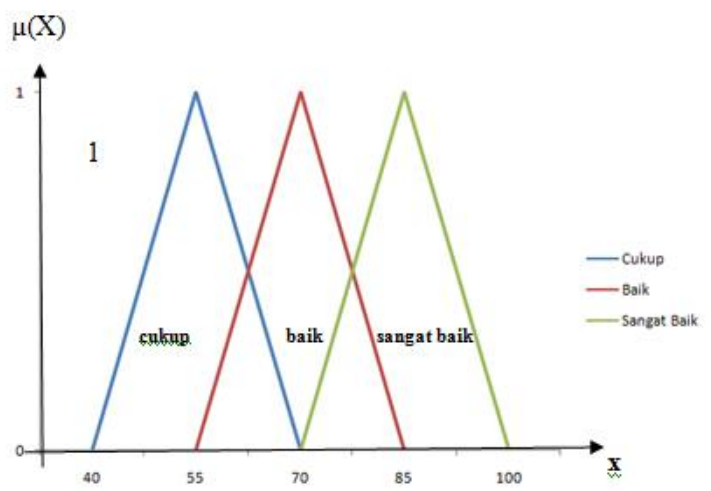

Gambar 4 Representas Fungsi Derajat Keanggotaan $(\mu) \mathrm{V}$ ariabel Input Nilai Bahasa Indonesia

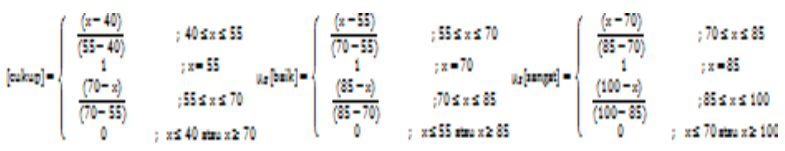

d. Fungsi Derajat Keanggotaan $(\mu) \mathrm{V}$ ariabel Input Nilai Bahasa Inggris

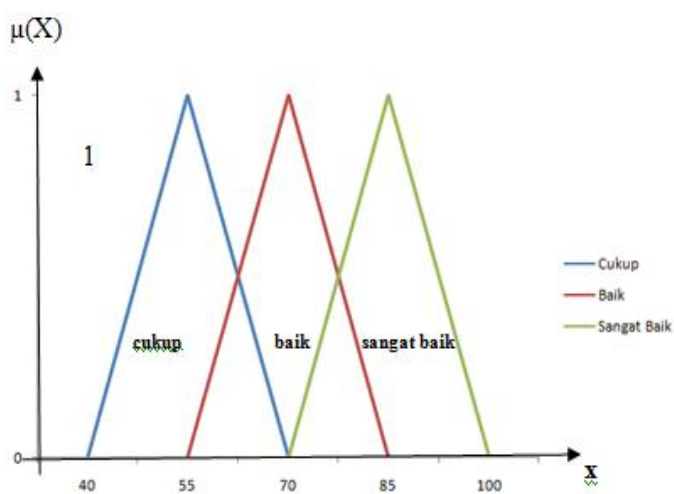

Gambar 5 Representas Fungsi Derajat Keanggotaan ( $\mu$ ) V ariabel Input Nilai Bahasa Inggris

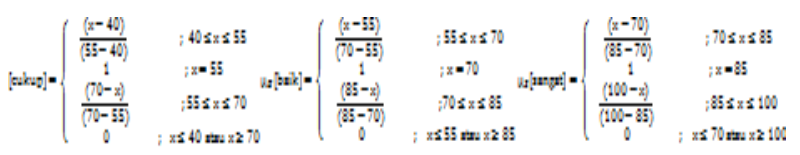

Berdasarkan tabel-table yang di atas, variabel rekomendasi jurusan yang dimana siswa akan tahu jurusan mana yang akan di masukinya. Gambar himpunan untuk variabel rekomendasi jurusan ditunjukkan pada gambar berikut : 
Tabel 5 Output Fuzzy

\begin{tabular}{|c|c|c|}
\hline Variabel & $\begin{array}{c}\text { Semesta } \\
\text { Pembicaraan }\end{array}$ & Keterangan \\
\hline TKJ & {$[0-100]$} & $\begin{array}{c}\text { Jumlah } \\
\text { Nilai }\end{array}$ \\
\hline RPL & {$[0-100]$} & $\begin{array}{c}\text { Jumlah } \\
\text { Nilai }\end{array}$ \\
\hline TSM & {$[0-100]$} & $\begin{array}{c}\text { Jumlah } \\
\text { Nilai }\end{array}$ \\
\hline TBO & {$[0-100]$} & $\begin{array}{c}\text { Jumlah } \\
\text { Nilai }\end{array}$ \\
\hline TKR & {$[0-100]$} & $\begin{array}{c}\text { Jumlah } \\
\text { Nilai }\end{array}$ \\
\hline KI & {$[0-100]$} & $\begin{array}{c}\text { Jumlah } \\
\text { Nilai }\end{array}$ \\
\hline
\end{tabular}

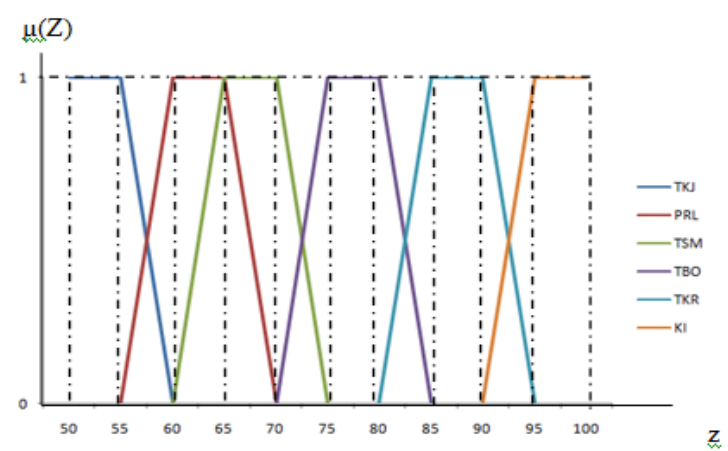

Gambar 6 Representasi Fungsi Derajat Keanggotaan ( $\mu$ ) Variabel Output

2. Penentuan Rule

Rules berupa pernyataan kualitatif yang ditulis dalam bentuk IF-THEN, sehingga mudah dimengerti.Rules pada Fuzzy Inference System (FIS) dalam memanajeman bandwidth internet didasari pada jumlah inputan dan jumlah himpunan fuzzy. Penentuan rules didasarkan pada pengujian secara manual dengan memperhitungkan probabilitas kemungkinan yang terjadi dengan kombinasi variabel.

Setelah tahap pembentukan variabel dan himpunan selesai dilakukan, maka tahap selanjutnya adalah pembentukan aturan fuzzy dengan menggunakan metode tsukamoto. Aturan ini dibentuk untuk menyatakan relasi antara input dan output, sehingga dapat dibentuk menjadi beberapa kombinasi yang menjadi aturan. Pembentukan aturan dihasilkan dari kombinasi tiap kondisi yang dikenal dengan aturan (rule) keputusan. Dan hasil perhitungan nya :

Adapun model dalam penentuan rule yang akan dirancang sebagai aturan dalam pembuatan rule.

Table 6 Variabel Nilai Siswa

\begin{tabular}{|c|c|c|c|c|}
\hline Variabel & $\begin{array}{c}\text { Niali } \\
\text { IPA }\end{array}$ & $\begin{array}{c}\text { Nilai } \\
\text { MM }\end{array}$ & $\begin{array}{c}\text { Nilai } \\
\text { B.Indo }\end{array}$ & $\begin{array}{c}\text { Nilai } \\
\text { B.Ing }\end{array}$ \\
\hline Nilai & 82 & 75 & 80 & 70 \\
\hline
\end{tabular}

Seorang siswa dengan Nilai mtk 82, Nilai b.indo 75 dan Nilai ipa 80 , Nilai b.ing 70 maka panitia pelaksanan akan melakukan uji seleksi untuk mengetahui tingkat kelulusannya dan rekomendasi kejurusannya.

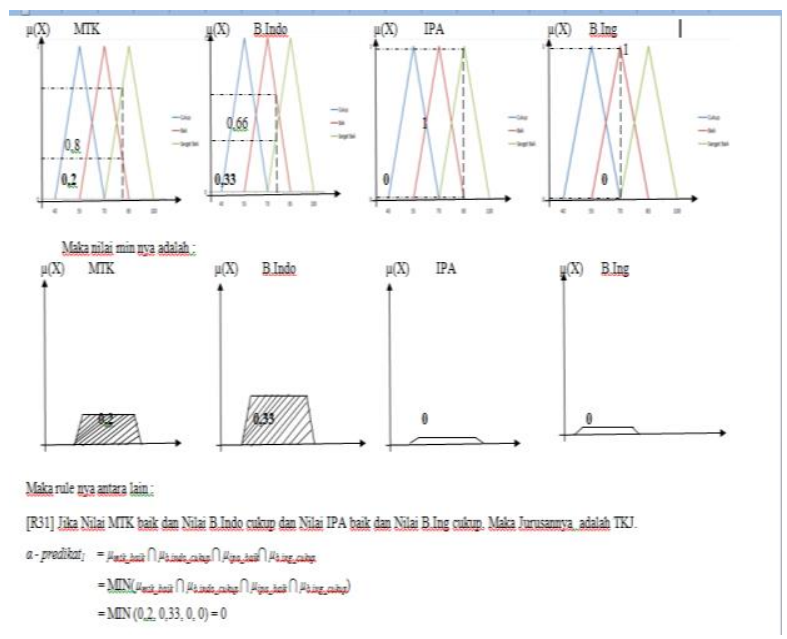

3. Proses Analisa Dan Rancangan

Dalam sistem rekomendasi jurusan ini ada dua activity diagram yaitu sebagai berikut. Activity Diagram Halaman Utama/ Home

Pada gambar tersebut menjelaskan aktifitas user untuk melihat halaman utama . User terlebih dahulu melihat menu halaman utama, kemudian sistem menampilkan tampilan halaman utama.

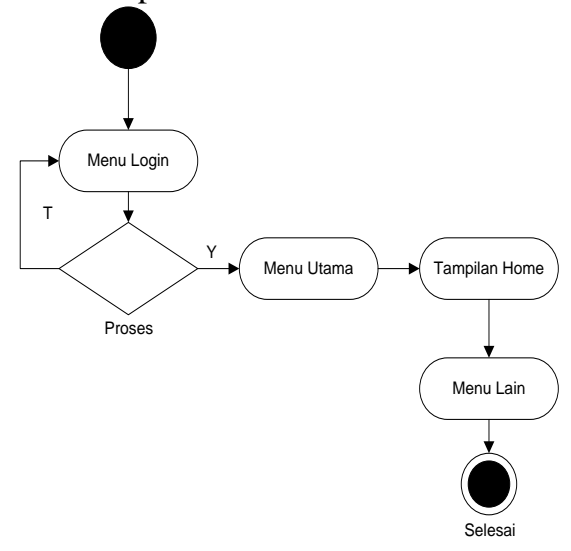

Activity Diagram Proses Rekomendasi Jurusan

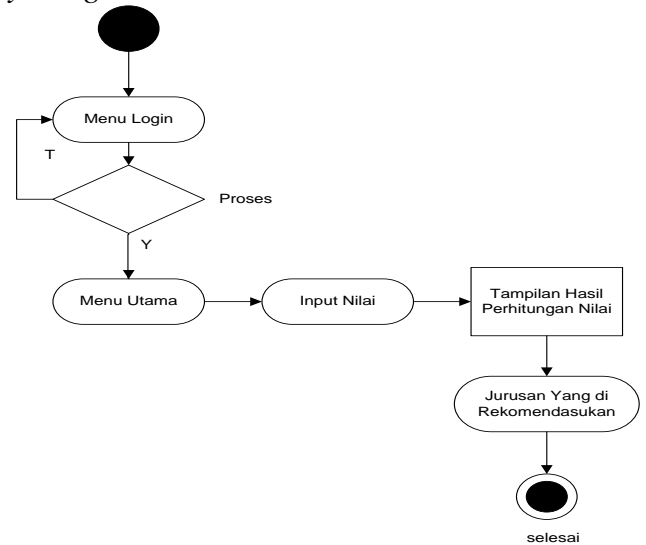


Pada gambar tersebut menjelaskan aktifitas admin masuk kedalam menu uatam aplikasi dan admin inputkan nilai siswa. Kemudian admin akan tau bahwasannya dia akan direkomendasikan ke jurusan yang akan sesuai dengan nilai yang dimiliki nya.

\section{Tampilan Program}

Adapun tampilan menu awal pada aplikasi yang telah dibuat antaralain adalah :

1. Tampialan Menu Login

Pada form ini merupakan gerbang untuk akses masuk kedalam aplikasi menu selanjutnya dimana bagi admin maupun pengguna (user) yang telah memiliki hak akses dapat menggunakan aplikasi ini.

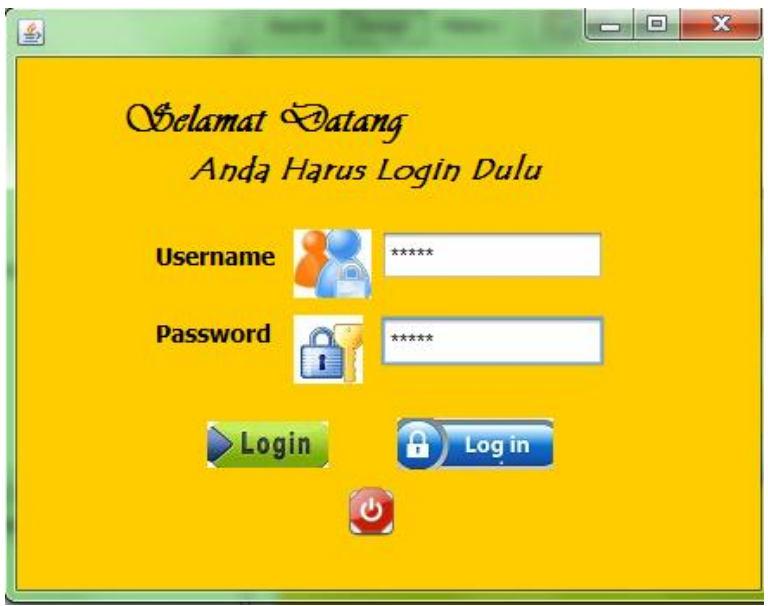

Gambar 7 Tampilan Desain Menu Login

Masukkan user ID dan Password pada kolom Password yang telah terdaftar di admin, lalu tekan tombol Login. Jika user ID dan Password yang dimasukkan benar, maka user dapat mengakses dan menggunakan Aplikasi tersebut, dan dimana menu tersebut ada juga login untuk siswa supaya dapat masuk dan melihat data mereka sendiri.

\section{Tampilan Desain Menu Utama (Home)}

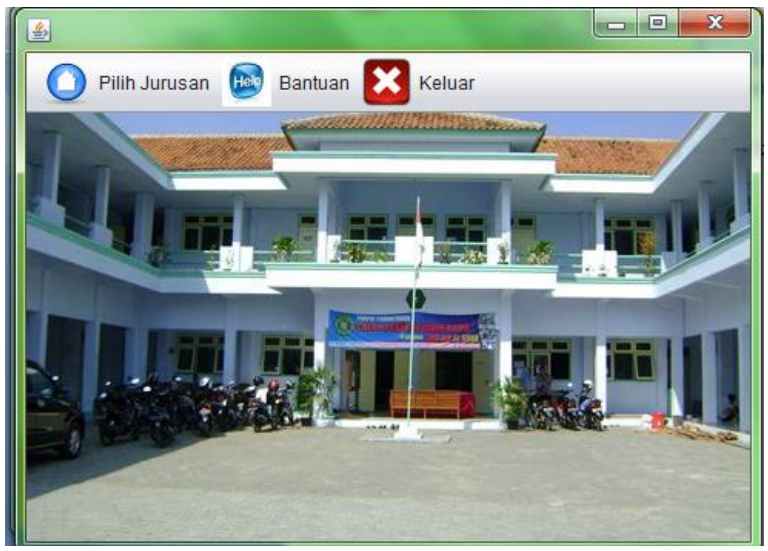

Gambar 8 Tampilan Desain Menu Home
Gambar diatas merupakan tampilan program sebelum data-data atau nilai siswa dimasukkan ke dalam program.

3. Tampilan Penentuan Jurusan

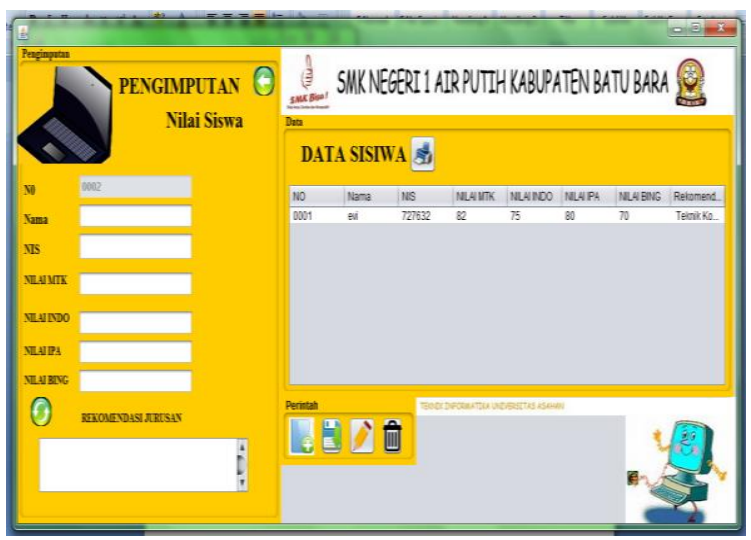

Gambar 9 Menu Tampilan Penentuan Jurusan

\section{KESIMPULAN}

Dari hasil penelitian yang telah dilakukan oleh penulis, maka dapat diambil beberapa kesimpulan antara lain:

1. Sistem implementasi yang dibuat dengan metode Tsukamoto mampu melakukan pemilihan jurusan sebagai mana yang telah direkomendasikan dengan berdasarkan nilai yang dimiliki oleh pengguna atau siswa. Sehingga siswa dapat masuk kedalam jurusan yang sesuai dengan kemampuan nya dengan melihat dari nilai yang telah dia peroleh.

2. Perhitungan yang telah dibuat dengan aplikasi NetBeans menunjukkan nilai yang sesuai dengan hasil penjumlahan fuzzy tsukamoto. Sehingga dimanfaatkan untuk menentukan jurusan bagi siswa baru Sekolah Menengah Kejuruan (SMK) N 1 Air Putih.

3. Aplikasi pemilihan jurusan yang dikembangkan dapat membantu siswa dalam memilih jurusan di Sekolah Menengah Kejuruan (SMK) N 1 Air Putih dengan kemungkinan hasil yang terbaik dan sangat memuaskan. Sehingga pemilihan jurusan tidak lagi dilakukan secara manual dan dengan asal pilih saja.

\section{DAFTAR PUSTAKA}

[1] Cakara AC., Hanny H., Desi P.K. dan Setia A. 2015. "Logika Fuzzy Menggunakan Metode Tsukamoto Untuk Prediksi Perilaku Konsumen di Toko Bangunan". Techno.COM. Vol. 14, No. 4, Hal. 255-2265.

[2] Hariri, F.R. 2016. "Penerapan Metode Fuzzy Sugeno Dalam Pendaftaran Siswa Baru di SDN 
Sonopatik 1 Nganjuk". Nusantara Of Enginering. Vol. 3, No. 1, Hal. 41-46. ISSN: 2355-6684.

[3] Khusnia D.dan Berlian K.R. 2014. "Pembuatan Website Profil Sekolah Menengah Pertama Negeri 1 Kalitidu Bojonegoro". IJNS-Indonesian Journal On Networking And Security. Vol. 3, No. 1, Hal. 1-6. ISSN: 2302-5700 (Print) 2354-6654 (Online).

[4] Kuncoro D.W. 2015. "Analisis Dan Perancangan Sistem Kasir Dan Pendataan Stok Barang Pada Tata Distro Pacitan”. Journal Speed - Sentra Penelitian Engineering Dan Edukasi. Vol. 7, No. 1, Hal. 40-46. ISSN : 1979-9330 (Print) - 20880154 (Online).

[5] Muhammad Dedi Irawan. 2017. Sistem Pendukung Keputusan Menentukan Matakuliah Pilihan pada Kurikulum Berbasis KKNI Menggunakan Metode Fuzzy Sugeno. Kisaran: Jurnal Media Infotama. Vol. 13, No. 1.27-35.

[6] Ningrum R. F. 2014. "Implementasi Logika Fuzzy Dalam Penentuan Pola Penggunaan Energi Listrik Pada Suatu Gedung Berdasarkan Hasil Audit Energi”. Jurnal Teknik. Vol. 3, No. 1, Hal. 44-52.

[7] Priyanti Dwi dan Siska Iriani. 2013. "Sistem Informasi Data Penduduk Pada Desa Bogoharjo Kecamatan Ngadirojo Kabupaten Pacitan". Indonesian Journal On Networking And Security. Vol. 2, No. 4, Hal. 55-61. ISSN: 2302-5700.

[8] Simanjuntak Magdalena dan Achmad Fauzi. 2017. "Penerapan Fuzzy Mamdani Pada Penialaian Kinerja Dose”. Jurnal ISD. Vol. 2, No. 2, Hal. 143-149. pISSN : 2477-863X, eISSN: $2528-5114$.

[9] Suryanto Angga. 2012. "Pembangunan Aplikasi Piket Pada Sekolah Menengah Atas Satu Kudus Berbasis Web". Journal Speed - Sentra Penelitian Engineering Dan Edukas. Vol. 4, No. 4, Hal. 2933. ISSN : $1979-9330$ (Print) - 2088-0154 (Online). 